\title{
"Venice marathon": participation of female Master Athletes shows a constant increase from 2003 to 2019
}

\author{
Giovanna Albertin (1,2), Laura Astolfi (1), Marco Falda (1), Davide Zuccon (3), \\ Barbara Ravara (1,2), Helmuth Kern (4,5,6), Giacomo Ferrante (7), Raffaele De Caro \\ $(1,2)$, Diego Guidolin (1)
}

(1) Department of Neuroscience (DNS), Section of Human Anatomy, University of Padova, Italy; (2) CIR-Myo - Interdepartmental Research Center of Myology, University of Padova, Italy; (3) Department of Biomedical Sciences (DBS), Bachelor's degree in physical education, University of Padova, Italy; (4) Physiko- und Rheumatherapie, St. Pölten, Austria; (5) Ludwig Boltzmann Institute of Rehabilitation Research, St Pölten, Austria; (6) Institute of Physical Medicine and Rehabilitation, Prim. Dr. H Kern GmbH, Amstetten, Austria; (7) School of biomedical engineering, University of Padova, Italy.

This article is distributed under the terms of the Creative Commons Attribution Noncommercial License (CC BY-NC 4.0) which permits any noncommercial use, distribution, and reproduction in any medium, provided the original author(s) and source are credited.

\begin{abstract}
The marathon is the most classic Olympic running event. In several cities worldwide it has become very popular with participation increasing during the last 20 years, particularly by Master Athletes. There are evidences that long-distance running could provide considerable health benefits for older runners, specifically risk reduction of cardiovascular diseases, cancer, diabetes, depression, and falls. Several studies have focused on the distribution of participants and their performance on famous marathons such as those of Berlin, Boston and New York. In this preliminary study we have analyzed data from several editions of the Venice marathon, a famous Italian race that attracts people from every corner of the world. The Venice marathon is listed in Abbott World Marathon Majors Wanda Age Group World Ranking and is Bronze Label certificated by IAAF, and Gold Label by FIDAL. The marathon starts outside Venice near Stra, then runs along the Brenta Riviera to Venice where the runners cross the canals over floating bridges set up for the race. For this study we analyzed data of the Venice marathon describing gender distribution in 17 editions (2003-2019), but groups of age-categories and their nationality only in 13 editions from 2007 to 2019. The analysis shows a steady increase in female participation, from 2003 to 2019.
\end{abstract}

Key Words: Paolo Gava; Venice Marathon; Master Athletes; gender and nationality.

Eur J Transl Myol 31 (4): 10266, 2021 doi: 10.4081/ejtm.2021 10266

To honor the key person who leaded our research group up to his premature passing in his beloved home in Stra (Venice) the night of July 19th, 2021, we decided to add to the Issue EJTM 31 (4), 2021 a preliminary report on the in-progress studies related to the Venice marathon, specifically on distribution of participants by gender in 17 editions of the Venice marathon from 2003 to 2019. In fact, without the generosity and skills of Paolo Gava, nothing of what is reported here and which we hope to continue to report in the future would have been possible. Paolo was a sustainable resources engineer, who worked in Italy, France, Netherlands and England, leading major research programs well before the fight against global warming became a world priority. After years of training as a semi-professional athlete, competing and winning short distance races in the 40-year-olds (Figure 1), and passionate about Tango, Paolo kept himself in shape by running and cycling. After his retirement from active sport, Paolo applied his engineering skills to optimize comparisons between the results of the different categories of Master Athletes, questioning the rules used by Italian and World Master Sports Associations. This hobby made him a successful amateur scientist during the last decade of his productive life and provided the foundation for an excellent method of comparing lifelong decay rates in different sports activities, particularly athletics events, including marathon. ${ }^{1}$

The marathon is the classic Olympic running event and in recent years, it has become very popular in several cities around the world with increasing participation rates. Record times have been improved with respect to endurance performance, sex ratio and physiological, 


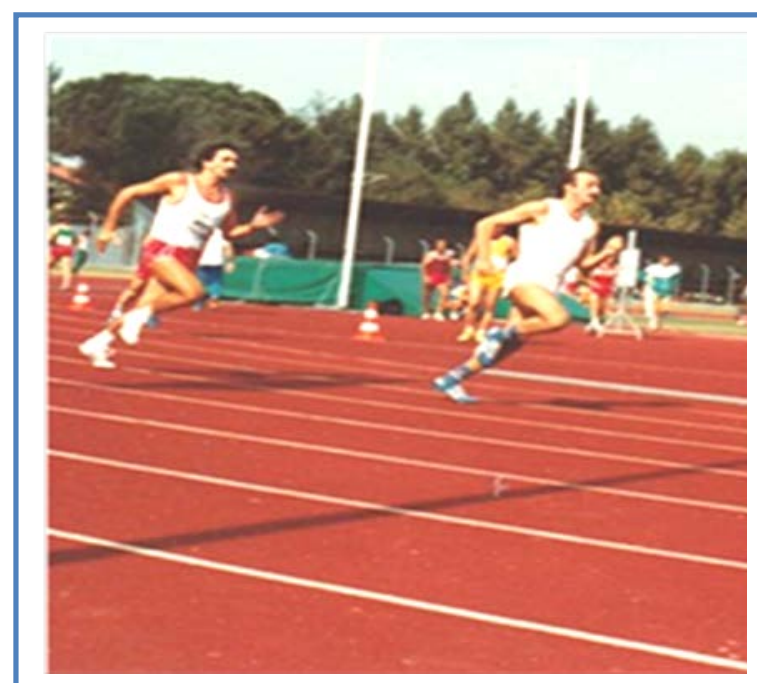

Fig 1. Paolo Gava (on the right), 400 meters 1990.

psychological and neurological aspects of physical activities. $^{2-8}$ The increased popularity of marathons has led to a significant increase in participants, particularly Master Athletes. ${ }^{9-12}$ There is evidence that long-distance running could provide considerable health benefits for older runners, such as risk reduction of cardiovascular diseases, cancer, diabetes, depression, and falls. ${ }^{13}$ Therefore, insight into pacing strategies for age group runners could be an important scientific breakthrough for sports and medicine practitioners specializing in treating senior as well as younger runners. Several studies have discussed the distribution and performance of participants in famous marathons such as Berlin, Boston and New York, events that attract large numbers of participants. They are useful models that can explain the success of recreational events. In this preliminary study, we analyze data from several editions of the Venice marathon, a famous Italian race that attracts people from all around the world. In this context, we want to analyze participation of Master Athletes as a human model of successful aging. ${ }^{14}$

\section{Materials and Methods}

As a former Master Athlete, often competing with FIDAL Association of Venice, Paolo Gava easily obtained from the president and the other organizers of the Venice marathon a long series of data to be analyzed with his dimensionless analysis method. ${ }^{15}$ In this preliminary study we report distribution of attendance by gender in the 17 editions from 2003 to 2019 and by age groups and nationalities in the 13 editions from 2007 to 2019 of the Venice marathon. The original data are free in timing data service (https://tds.sport/it/). ${ }^{16}$

\section{Results and Discussion}

Venice marathon saw its first edition in 1984. It is part of the Abbott World Marathon Majors Wanda Age Group World Ranking and it is worldwide recognized and Bronze Label certificated by IAAF, and Gold Label by
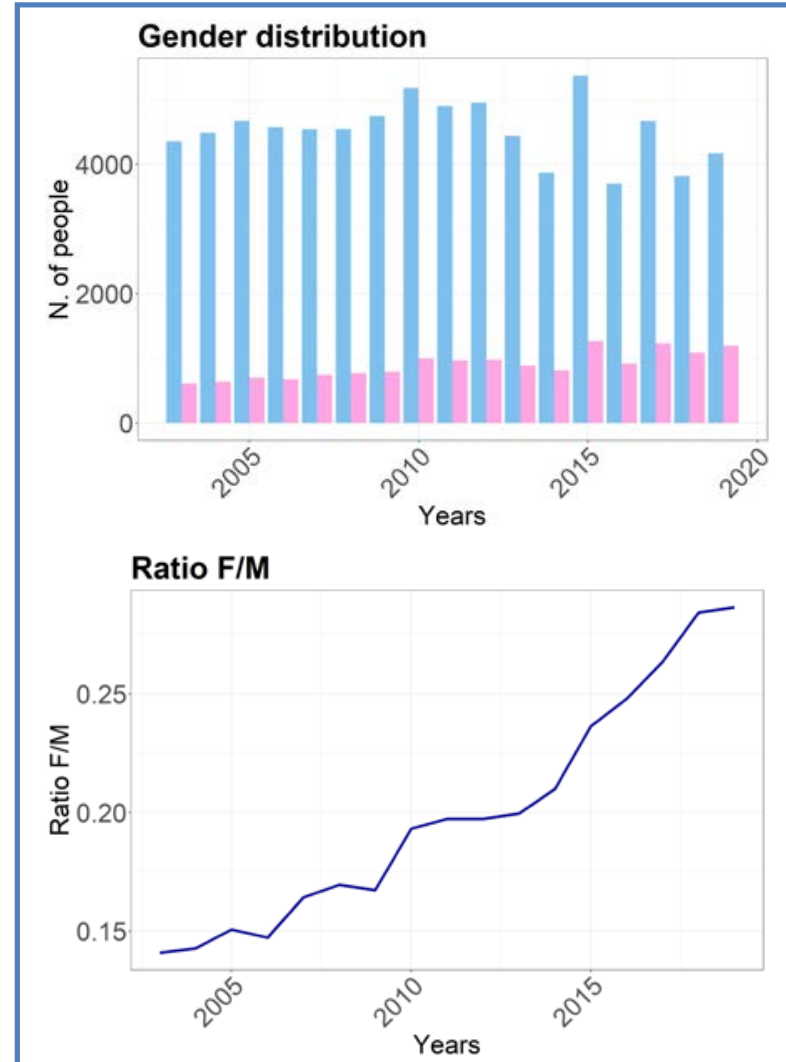

Female distribution in percentage

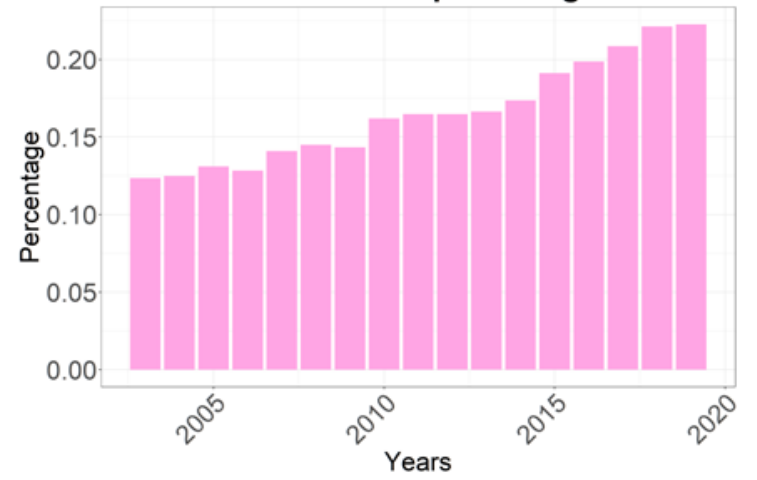

Fig 2. Total participation from 2003 to 2019 was 92.405 in these 17 editions of Venice marathon (annual average $5430 \pm 536$ ) with no significant variations between the 17 editions. Upper panel: gender distribution. Middle panel: ratio F/M. Lower panel: female distribution in percentage.

FIDAL. The race starts near Stra (Venice), runs along the Brenta Riviera to Venice where it crosses the town canals with floating bridges set up specifically for the race. Since 1994, to preserve the safety of participants and the integrity of the city, the enrollment was limited to 6000 . Since this is an event with a limited number of athletes, the total participation from 2003 to 2019 was 92.405 across those 17 editions of Venice marathon (annual average $5430 \pm 536$ ), with no significant variations between the 17 editions (Figure 2, upper panel). The 


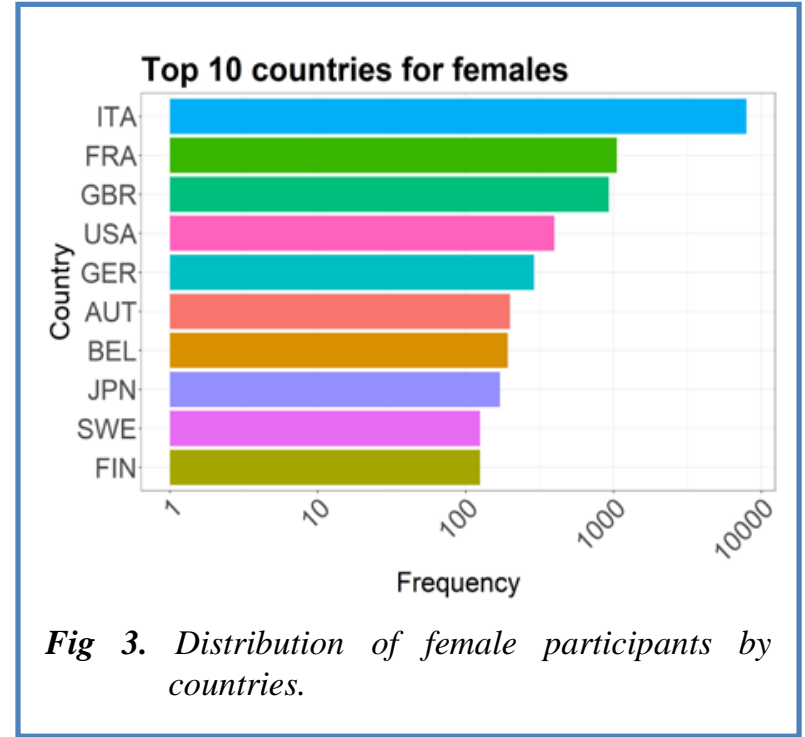

average percentage of male participation was $83.5 \%$ and the female participation was $16.5 \%$ with an average of $4530 \pm 456$ male and $899 \pm 207$ female participants.

The ratio (R) between female and male participants, obtained as the number of female participants over the male ones, showed a linear and significant $(\mathrm{p}<0.0001$, linear regression analysis) increase (Figure 2, middle panel). The minimum ratio was in $2003(\mathrm{R}=0.141)$ and the best is in $2019(\mathrm{R}=0.287)$. The significant increase in female participation $(\mathrm{p}<0.0001)$ went from a minimum of 614 in 2003 to a maximum of 1270 in the 2015 edition, which corresponds to an increase of $106 \%$ (Figure 2, lower panel). The female participants increased from $12.4 \%$ in 2003 to $22.3 \%$ in 2019 , the last event before the lockdown for the COVID19 pandemic.

The distribution of participants by country indicated that $77 \%$ of participants were of Italian nationality and 23\% of European and non-European countries. Figure 3 shows the nations most represented among women: Italy is followed by France, Great Britain and the United States. The age group analysis has shown that in the 13 years between 2007 and 2019, the groups between 40 and 55 years old, both men and women, were the most numerous to indicate an important participation of people that still wants to continue to run after an athlete life or more probably, marathons attract people who start running for different reasons and only later find the personal motivation to tackle a marathon (Figure 4).

Physical activity and sport participation can have a variety of physiological benefits that reduce or even reverse the age-related declines in muscle mass, strength and performance. ${ }^{17,18}$ Thus the most obvious reasons why people run are the positive effects on health and mental wellbeing. The benefits of weight loss and cardiovascular health are well known. More recently, training for and completing a marathon event even at low exercise intensity was shown to reduce central blood pressure and aortic stiffness. ${ }^{19}$ Indeed, in a recent study authors have found a possible relationship between cognitive

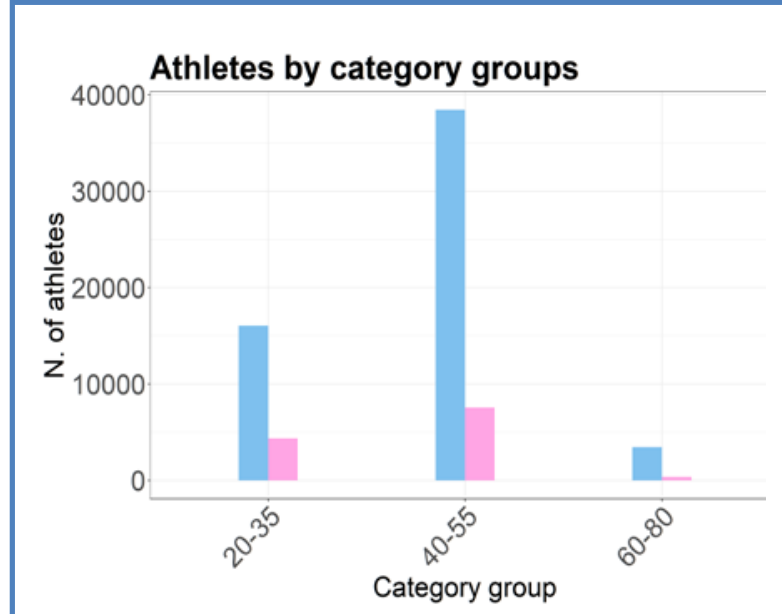

Fig 4. Distribution of participants by age groups

performance in high-demand tasks and retinal vasculature, i.e., a positive neuroplastic effect of exercise. ${ }^{20}$ It is known that performance decreases with age, but here the increase in the number of female participants confirms that running is a sport that everyone can practice and in which women will become protagonists in the near future. These data about participants are in line with those shown in the Marathon Statistics 2019 worldwide report, ${ }^{21}$ which assessed the distribution of participants and marathon performances in 30 countries around the world, taking into account over thirty thousand races held between 2008 and 2018. As far as the gender distribution in Italy is concerned, the male participation was $85 \%$ and the female participation $15 \%$. The model of the Venice marathon can therefore be used to also analyze the performance of participants, as Paolo Gava began to do with other types of models. ${ }^{15,22}$ Thanks Paolo, we will never forget your generosity and positive approach to life.

\section{List of acronyms}

FIDAL - Federazione Italiana Di Atletica Leggera

IAAF - International Association of Athletics Federation WMA - World Masters Athletics

\section{Authors' contributions}

GA, LA, MF, DZ, BR, HK, GF, RDC, DG: drafting, writing and approval of the final typescript.

\section{Acknowledgments}

The authors warmly thank the organizers of the Venice marathon for data on participants and other relevant information on the race route.

\section{Funding}

None

\section{Conflict of Interest}

The authors declare no competing interests. 


\section{Ethical Publication Statement}

We confirm that we have read the Journal's position on issues involved in ethical publication and affirms that this report is consistent with those guidelines.

\section{Corresponding Author}

Giovanna Albertin, Department of Neuroscience, Section of Human Anatomy, University of Padova, Via Belzoni 160, 35131 Padova, Italy.

ORCID iD: 0000-0002-7551-4431

E-mail: giovanna.albertin@unipd.it

\section{E-mails and ORCID iD of co-authors}

Laura Astolfi: laura.astolfi@unipd.it ORCID iD: 0000-0002-3291-8567

Marco Falda: marco.falda@unipd.it ORCID iD: 0000-0003-2642-519X

Davide Zuccon:davide.zuccon@studenti.unipd.it ORCID iD: 0000-0001-7847-866X

Barbara Ravara:barbara.ravara@unipd.it

ORCID iD: 0000-0002-0159-3245

Helmut Kern: helmut@kern-reha.at

ORCID iD: 0000-0001-9661-8814

GiacomoFerrante: giacomo.ferrante@studenti.unipd.it

ORCID: 0000-0002-7265-6311

Raffaele De Caro: raffaele.decaro@unipd.it ORCID: 0000-0002-2307-0277

Diego Guidolin: diego.guidolin@unipd.it

ORCID iD: 0000-0002-7551-4431

\section{References}

1. Carraro U, Kern H, Albertin G. Paolo Gava, a professional engineer, who has become a Master athlete, an amateur scientist and a lifelong friend. Eur J Transl Myol. 2021 Nov 5. doi: 10.4081/ejtm.2021.10260. Epub ahead of print.

2. Stones MJ. Age Differences, Age Changes, and Generalizability in Marathon Running by Master Athletes. Front Psychol. 2019 Sep 20;10:2161. doi: 10.3389/fpsyg.2019.02161.

3. Roelands B, de Koning J, Foster C, Hettinga F, Meeusen R. Neurophysiological determinants of theoretical concepts and mechanisms involved in pacing. Sports Med. 2013 May;43(5):301-11. doi: 10.1007/s40279-013-0030-4.

4. Deaner RO, Carter RE, Joyner MJ, Hunter SK. Men are more likely than women to slow in the marathon. Med Sci Sports Exerc. 2015 Mar;47(3):607-16. doi: 10.1249/MSS.0000000000 000432.

5. Coyle EF. Physiological regulation of marathon performance. Sports Med. 2007;37(4-5):306-11. doi: 10.2165/00007256-200737040-00009.

6. Cheung SS, McLellan TM, Tenaglia S. The thermophysiology of uncompensable heat stress. Physiological manipulations and individual characteristics. Sports Med. 2000 May;29(5):32959. doi: 10.2165/00007256-200029050-00004.

7. Druyan A, Makranz C, Moran D, Yanovich R, Epstein Y, Heled Y. Heat tolerance in women-reconsidering the criteria. Aviat Space Environ Med. 2012 Jan;83(1):58-60. doi: 10.3357/asem. 3130.2012. Erratum in: Aviat Space Environ Med. 2012 Feb;83(2):155. Amit, Druyan [corrected to Druyan, Amit]; Yuval, Heled [corrected to Heled, Yuval].

8. Garrett AT, Goosens NG, Rehrer NJ, Patterson MJ, Harrison J, Sammut I, Cotter JD. Short-term heat acclimation is effective and may be enhanced rather than impaired by dehydration. Am J Hum Biol. 2014 May-Jun;26(3):311-20. doi: 10.1002/ajhb.22509. Epub 2014 Jan 28.

9. Running USA. Available online: https://www.runningusa.org// (accessed on 15 February 2019).

10. Anthony D, Rüst CA, Cribari M, Rosemann T, Lepers R, Knechtle B. Differences in participation and performance trends in age group half and full marathoners. Chin J Physiol. 2014 Aug 31;57(4):209-19. doi: 10.4077/CJP.2014.BAC219.

11. Nikolaidis PT, Cuk I, Rosemann T, Knechtle B. Performance and Pacing of Age Groups in HalfMarathon and Marathon. Int J Environ Res Public Health. 2019 May 20;16(10):1777. doi: 10.3390/ijerph16101777.

12. Leyk D, Erley O, Gorges W, Ridder D, Rüther T, Wunderlich M, Sievert A, Essfeld D, Piekarski C, Erren T. Performance, training and lifestyle parameters of marathon runners aged 20-80 years: results of the PACE-study. Int J Sports Med. 2009 May;30(5):360-5. doi: 10.1055/s-0028-1105935. Epub 2009 Mar 10.

13. Marzetti E, Calvani R, Tosato M, Cesari M, Di Bari M, Cherubini A, Broccatelli M, Savera G, D'Elia M, Pahor M, Bernabei R, Landi F; SPRINTT Consortium. Physical activity and exercise as countermeasures to physical frailty and sarcopenia. Aging Clin Exp Res. 2017 Feb;29(1):35-42. doi: 10.1007/s40520-016-0705-4. Epub 2017 Feb 8.

14. Lepers R, Cattagni T. Do older athletes reach limits in their performance during marathon running? Age (Dordr). 2012 Jun;34(3):773-81. doi: 10.1007/s11357-011-9271-z. Epub 2011 May 27.

15. Gava P, Kern H, Carraro U. Age-associated power decline from running, jumping, and throwing male masters world records. Exp Aging Res. 2015;41(2):115-35. doi: 10.1080/0361073X. 2015.1001648.

16. Timing data service TDS Sport. Available online: https://tds.sport/it/ (accessed on 15 February 2019).

17. Kanamori S, Kai Y, Kondo K, Hirai H, Ichida Y, Suzuki K, Kawachi I. Participation in sports organizations and the prevention of functional disability in older Japanese: the AGES Cohort 
Female Master athletes in Venice marathon

Eur J Transl Myol 31 (4): 10266, 2021 doi: 10.4081/ejtm.2021.10266

Study. PLoS One. 2012;7(11):e51061. doi: 10.1371/journal.pone.0051061. Epub 2012 Nov 30.

18. Fien S, Henwood T, Climstein M, Keogh JW. Feasibility and benefits of group-based exercise in residential aged care adults: a pilot study for the GrACE programme. PeerJ. 2016 May 18;4:e2018. doi: 10.7717/peerj.2018.

19. Bhuva AN, D'Silva A, Torlasco C, Jones S, Nadarajan N, Van Zalen J, Chaturvedi N, Lloyd G, Sharma S, Moon JC, Hughes AD, Manisty CH. Training for a First-Time Marathon Reverses AgeRelated Aortic Stiffening. J Am Coll Cardiol. 2020 Jan 7;75(1):60-71. doi: 10.1016/j.jacc.2019. 10.0455 .

20. Roeh A, Schoenfeld J, Raab R, Landes V, Papazova I, Haller B, Strube W, Halle M, Falkai P, Hasan A, Scherr J. Effects of Marathon Running on
Cognition and Retinal Vascularization: A Longitudinal Observational Study. Med Sci Sports Exerc. 2021 Oct 1;53(10):2207-2214. doi: 10.1249/MSS.0000000000002699.

21. Marathon Statistics 2019 Worldwide (Research) | RunRepeat. Available online: https://runrepeat. com/research-marathon-performance-acrossnations. (accessed on 15 February 2019).

22. Gava P, Giuriati W, Ravara B. Gender difference of aging performance decay rate in normalized Masters World Records of Athletics: much less than expected. Eur J Transl Myol. 2020 Apr 1;30(1):8869. doi: 10.4081/ejtm.2019.8869.

Submitted: November 04, 2021 Accepted for publication: November 04, 2021 